Esta publicación cientifica en formato digital es continuidad de la revista impresa ISSN-Versión Impresa 0798-1406 / ISSN-Versión on line 2542-3185Depósito legal pp
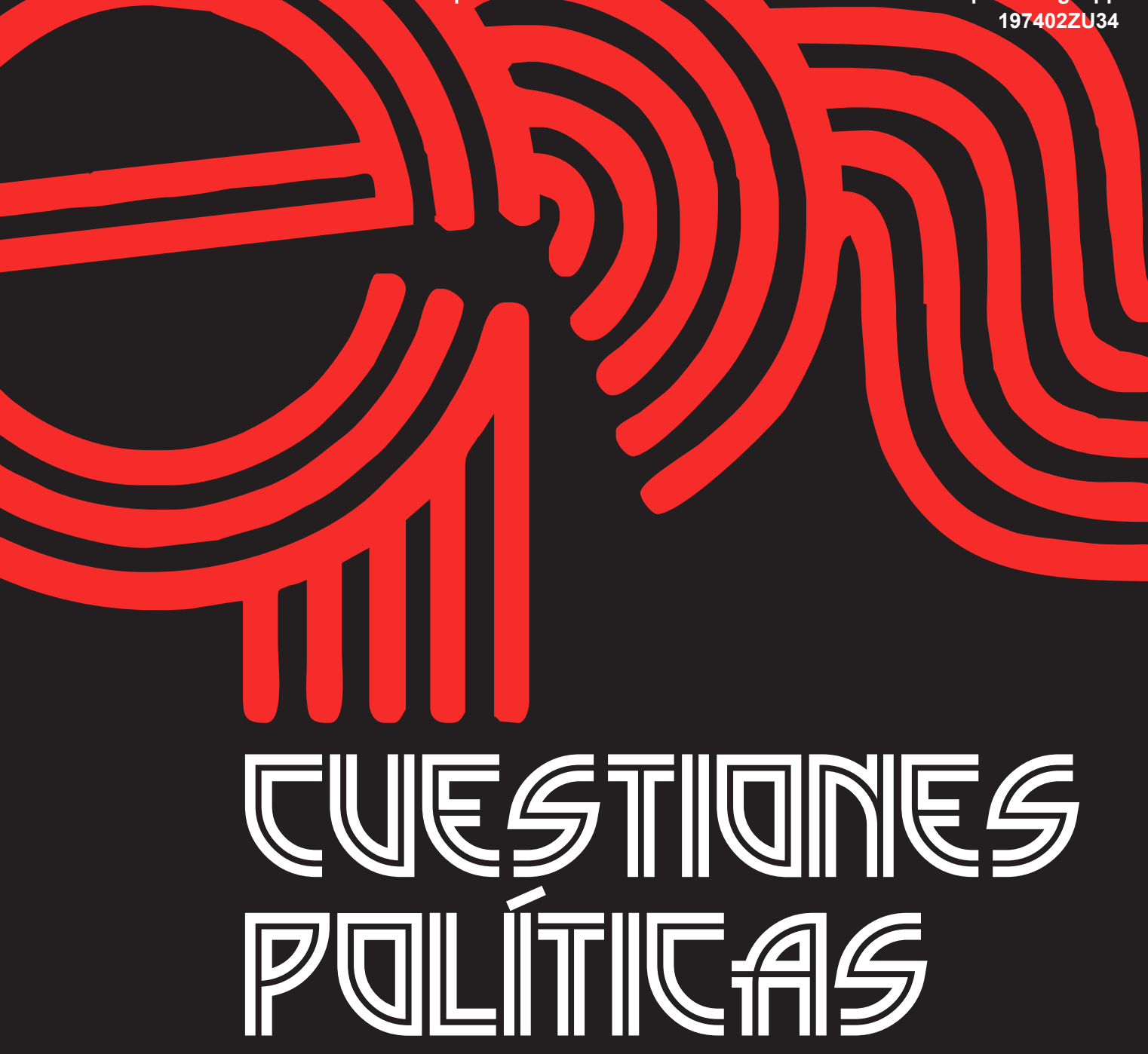

Instituto de Estudios Políticos y Derecho Público "Dr. Humberto J. La Roche" de la Facultad de Ciencias Jurídicas y Políticas de la Universidad del Zulia Maracaibo, Venezuela
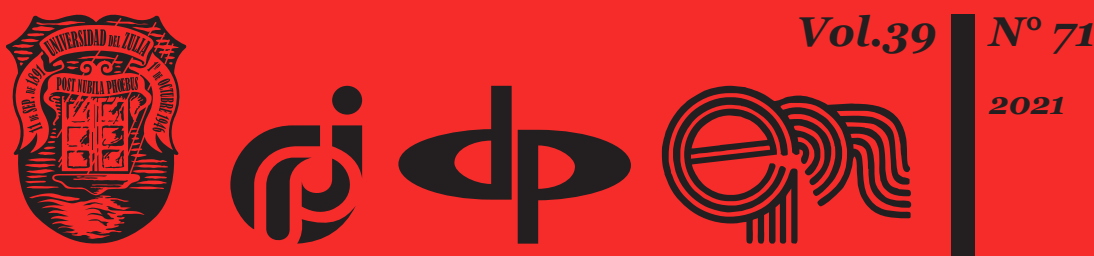


\title{
Apuntes para la crítica del discurso progresista históricamente existente
}

\author{
DOI: https://doi.org/10.46398/cuestpol.3971.29
}

\author{
Krylova Svitlana * \\ Lesia Levchenko ** \\ Sulieimanova Liia *** \\ Ulyana Khanas **** \\ Larysa Kharchenko *****
}

\section{Resumen}

Desde una metodología hermenéutica dialéctica que discute distintos textos ideológicos producidos en particulares contextos políticos de poder, el objetivo del artículo radica en definir una línea crítica que señala inconsistencias y contradicciones ante lo que genéricamente puede definirse sin mucha precisión conceptual como discurso progresista, esto es: una formación discursiva que agrupa a distintos movimientos sociales, organizaciones civiles y partidos políticos --en teoría-- de franco carácter contrahegemónico. Se concluye que moralmente el discurso progresista no es por sí mismo malo, bueno, ni neutral, todo dependerá, en último término, de los gustos y preferencias de cada persona construidos mediante sus sesgos culturales y, más específicamente, al calor de los procesos de socialización política por los que han sido condicionados ontológicamente. Por lo tanto, más que una crítica del discurso progresista históricamente existente, se debe efectuar una revisión a la forma tendenciosa mediante la cual ciertos actores políticos usan este discurso para validar sus intereses hegemónicos en su contexto de actuación. Además, en muchos aspectos verificables este discurso puede

* Doctor of Philosophy, Professor of Department of Culturology and Philosophical Anthropology, National Pedagogical Dragomanov University, Kyiv, Ukraine. ORCID ID: https://orcid.org/ooooooo2-5528-7438. Email: lana.swetly@gmail.com

** Ph.D. in Philosophy, Associate Professor, Associate Professor of Philosophy and Social Anthropology named after Professor I.P.Stogny, Hryhorii Skovoroda University in Pereiaslav, Pereiaslav. ORCID ID: https://orcid.org/oooo-0oo2-9919-9018. Email: les17ya@gmail.com

*** Ph.D. of Philosophical Sciences, Senior science officer, Department of scientific and educationalmethodical support of the content of preschool and primary education in the New Ukrainian school of the State Scientific Institution «Institute of education content modernization», Kyiv, Ukraine. ORCID ID https://orcid.org/oooo-0001-7801-4507. Email: liya8vera@gmail.com

**** Ph.D. in Philosophy, Associate Professor, State University «Uzhhorod National University», Associate Professor of Philosophy Department, Uzhhorod, Ukraine. ORCID ID: https://orcid.org/oooo-0oo28691-3809. Email: ulyana.hanas@uzhnu.edu.ua

****** Ph.D. in Philosophy, Associate Professor, Associate Professor of Philosophy and Social Anthropology named after Professor I.P.Stogny, Hryhorii Skovoroda University in Pereiaslav, Pereiaslav, Ukraine. ORCID ID: https://orcid.org/oooo-0002-5731-0531. Email: harchenko_lora@ukr.net 
significar la justificación de prácticas autoritarias que contravienen el goce y disfrute de derechos fundamentales, lo que no significa que los autores apuesten por posiciones políticas e ideológicas conservadoras.

Palabras clave: pensamientos crítico latinoamericano; discurso progresista; izquierda latinoamericana; violaciones a los derechos humanos; estudios latinoamericanos en Europa.

\title{
Notes for the critique of the historically existing progressive discourse
}

\begin{abstract}
From a dialectical hermeneutic methodology that discusses different ideological texts produced in particular political contexts of power, the objective of the article lies in defining a critical line that points out inconsistencies and contradictions before what generically can be defined without much conceptual precision as progressive discourse, that is: a discursive formation that brings together different social movements, civil organizations and political parties --in theory-- of frank counter-hegemonic character. It is concluded that morally the progressive discourse is not by itself bad, good, or neutral, everything will depend, ultimately, on the tastes and preferences of each person built by their cultural biases and, more specifically, in the heat of the processes of political socialization by which they have been conditioned ontologically. Therefore, rather than a critique of the historically existing progressive discourse, a review must be made of the tendentious way in which certain political actors use this discourse to validate their hegemonic interests in their context of action. In addition, in many verifiable respects this discourse can mean the justification of authoritarian practices that contravene the enjoyment and enjoyment of fundamental rights, which does not mean that the authors bet on conservative political and ideological positions.
\end{abstract}

Keyword: Latin American critical thinking; progressive discourse; Latin American left; human rights violations; Latin American studies in Europe. 


\section{Introducción}

Probablemente se puede definir el discurso progresista como una formación discursiva ${ }^{6}$ que articula dialécticamente, y en algunos casos sin mucha consistencia, distintas narrativas de franco carácter contrahegemónico para revindicar los derechos de minorías e identidades etno-sociales históricamente relegadas-oprimidas por el orden establecido, tales como: la comunidad LGBT, los pueblos ancestrales, las mujeres, los pobres, los ecologistas, los migrantes y los animalistas, entre otros muchos (Nikitenko et al., 2021).

Todo indica que el discurso progresista es el punto nodal de una agenda política internacional que según Ruiz, (2015) maneja tópicos reiterativos como: el aborto, la eutanasia, el matrimonio igualitario y la defensa de estilos de vida alternativos en función de los intereses de las identidades sociopolíticas emergentes que se posicionan en cada momento como opuestas a los valores neoconservadores de la sociedad moderna-burguesa, razón por la que en muchos sentidos se trata de una narrativa postmoderna ${ }^{7}$ que tiende a erosionar los valores de la modernidad al tiempo que sintetiza y/o resignifica la tradición socialista del siglo $\mathrm{XX}$, en sus dicotomías conceptuales al estilo de: explotados/explotadores, ricos/pobres, capitalistas/socialista, democracias burguesas/democracias populares, con la diferencia que incluye en sus núcleos de significado nuevos actores, temas y contextos desde múltiples lugares de enunciación que difícilmente pueden configurar una unidad monolítica, de ahí que la misma categoría de discurso progresista pueda resultar problemática cuando se la aborda desde una perspectiva científica, dada su creciente polisemia.

De cualquier modo y para los efectos particulares de este artículo por discurso progresista entendemos a un tipo de discurso político que según Muñoz (2004) se identifica por ciertos patrones argumentativos estables sobre las formas de democratizar y descentralizar el poder, en el marco de una reflexión tacita sobre el desmantelamiento de las hegemonías que, agregamos nosotros, cuestiona el accionar de las elites políticas, económicas

6 Según Vasilachis de Gialdino (1998), Irene, Discurso político y prensa escrita, un análisis sociológico, Jurídico y lingüístico, Gedisa editorial, Barcelona, pp.31-32, Michel Foucault supone que: “...cierto número de enunciados, semejante sistema de dispersión, en el caso de que, entre los objetos, los tipos de enunciados, los conceptos, las elecciones temáticas, se pudiera definir una regularidad (un orden, correlaciones, posiciones en funcionamiento, transformaciones), se dirá por convención, que se trata de una formación discursiva. En este sentido, dentro una formación discursiva se encuentra interconectados una gran cantidad de narrativas, discursos y relatos que pueden llegar a transcender limites espaciales, temporales e ideo-políticos.

7 Se habla de una narrative postmoderna en el sentido que lo refiere Lyotard (1987), como un discurso que desconoce los elementos primarios o ideas constitutivas de las modernidad occidental, estos es: el cristianismo y sus instituciones religiosas como espacios para la trascendencia espiritual; la posibilidad ilimitada del progreso científico y social basado en una concepción instrumental de la razón y, por último; la supuesta capacidad de las ideologías políticas como el socialismo o liberalismo para liberar a la persona humana de todo lo que entorpece el desarrollo autónomo de su personalidad. 
y religiosas de una sociedad determinada y, al mismo tiempo, propende en la perspectiva simbólica y material a la creación de espacios de democracia radical de base que acerquen a los colectivos organizados a la toma de decisiones prescindiendo, si es preciso, de las instituciones burocráticas tradicionales y de los políticos profesionales.

El objetivo del artículo radica en definir una línea crítica que señala inconsistencias y contradicciones en el discurso progresista, al menos en el plano del análisis teórico, toda vez que un estudio más específico requiere como condición de posibilidad para su realización de la selección amplia de una muestra discursiva de distintos sujetos políticos en su contexto, cosa que se hace muy tímidamente, por ello, el presente ensayo esta más próximo a la reflexión filosófica que el dato empírico típico del análisis del discurso. Especialmente el objetivo planteado se traduce en las preguntas ¿Cuáles son las principales inconsistencias del discurso progresista en líneas generales? ¿hasta qué punto estas inconsistencias pueden significar la justificación de prácticas autoritarias que contravienen el goce y disfrute de derechos fundamentales en personas y comunidades enteras? ¿es el discurso Progresista un producto cultural novedoso?

El articulo está dividido en cuatros secciones interconectadas al propósito de responder al objetivo de la investigación: en la primera y luego de la introducción, se aclaran los aspectos teóricos y metodológicos que permiten entender el desarrollo del artículo; en la segunda, se describen las característica generales del discurso progresista en Latinoamérica; en la tercera, se analiza como ciertos discursos en concreto sirven para construir una nueva hegemonía que oprime a personas y comunidades enteras, aunque retóricamente dice propender a su liberación. Por último, se muestran las conclusiones del estudio.

\section{Aclaratoria teórica y metodológica}

Desde al menos tres décadas los estudios del discurso en general y el de tipo político, en particular, ocupan un lugar destacado en disciplinas como la filosofía del lenguaje, la lingüística, la pragmática, la semiótica y la filología. Sin embargo, no sería adecuado afirmar que se trate de un campo de estudio monopolizado por un específico campo del saber científico, se trata más bien de un espacio de franco carácter inter y transdisciplinario en el que confluyen científicos y especialistas de las más variadas disciplinas de las ciencias sociales y humanas interesados grosso modo en develar la relación lenguaje y poder, bajo el supuesto que toda estructura de poder, tiene a su servicio un aparato comunicacional que lo justifica y lo racionaliza por ante las masas. 
En este orden de ideas, no existe un método univoco para abordar el fenómeno de la discursividad en un tiempo y espacio determinado, sino una multiplicidad de herramientas con protocolos particulares para procesar la información que incluso pueden combinarse, tales como: la hermenéutica dialéctica, la fenomenología, el análisis crítico del discurso político (ACDP), el análisis de contenido o las historias de vida. En todos los casos aludidos se postula que:

La definición del discurso como lengua en uso es coherente con el funcionalismo en general: se ve al discurso como un sistema (como una forma de hablar social y culturalmente organizada) a través de la cual se realizan funciones particulares. Si bien pueden muy bien examinarse regularidades formales, una definición funcionalista del discurso aleja al analista de las bases estructurales de dichas regularidades para centrarse en el modo en que los patrones del habla se usan para ciertos propósitos en contextos particulares, y/o de qué modo dichos patrones resultan de la aplicación de estrategias comunicativas (Schiffrin, 2011: 16).

A pesar de su tendencia excesivamente funcionalista, se extrae de la cita que el discurso es un producto simbólico que se manifiesta en el orden social como un sistema intersubjetivo mediante al cual se realizan funciones comunicativas particulares en el marco de una cultura con valores y prácticas que dotan de significado e identidad a grupos de personas. No obstante, desde nuestro punto de vista, aunque la realidad sea una construcción social forjada en buena medida por la ontología del lenguaje ${ }^{8}$, conviene diferenciar, en cada momento, entre lenguaje y realidad, es decir, entre el discurso como instrumento ideológico para justificar ciertos intereses de poder, de la realidad misma que victimiza con sus contradicciones a ingentes grupos de personas subordinadas por el poder, incluso aunque este poder se exprese mediante una narrativa a tono con los parámetros del discurso progresista.

Sin esta diferenciación como entender por ejemplo el fracaso estrepitoso de la experiencia histórica del socialismo real en la URSS o, más recientemente, como valorar la crisis humanitaria compleja acontecida en la Venezuela del siglo XXI, liderada por un gobierno que se auto percibe como socialistas y comprometido con los pobres y marginados, de hecho, ¿̇cómo negar la condición totalitaria de las estructuras políticas del socialismo marxista en el mundo? , más allá de su narrativa propagandística.

Por su parte, Soler (2011) propone desde la teoría de la argumentación entender el discurso político como un marco donde confluyen las relaciones de poder cuyo propósito sería convencer a la audiencia de la viabilidad y pertinencia de determinadas tesis sobre la política y lo político, es decir,

8 Esta es la tesis de Echeverría (2003), para quien el lenguaje es la esencia misma de toda realidad, de modo que la diferencia entre discurso y realidad se daría solo en el plano analítico más que en los mundos de vida de las personas. 
la vida de la polis moderna y, justificar una gestión de gobierno. En este punto, agregamos nosotros, la tesis que reproduce y reproduce el poder hegemónico en los medios de comunicación de masas no se sustenta, en muchos casos conocidos, en datos solidos o evidencia empírica verificable, por el contrario, se apela a la emocionalidad de la audiencia y a permear se estructura afectiva como condición de posibilidad para persuadirlos y convencerlos, incluso, a contravía de sus propios intereses. Esto explica como un grupo importante de votantes se aferran de forma vehemente a partidos y lideres carismáticos en el ejercicio del poder, de izquierda o de derecha, que sistemáticamente erosionan sus condiciones de vida y deterioran el bienestar social.

En cuanto a la definición de discurso progresista, como discurso político de nueva hegemonía un balance sistemático de búsqueda por Google académico demuestra que esta categoría ha sido poco estudia, al menos en Latinoamérica, tal como lo evidencian los pocos resultados sobre el tema. En consecuencia, el discurso progresista es estudiado en la región más bien como un epifenómeno de otros temas, a diferencia de lo sucedido en Europa donde abundan las fuentes sobre el tema.

El artículo de investigación que hoy se presenta se inscribe en la tradición filosófica de la hermenéutica que, según Gadamer (1993), puede significar una metodología novedosa para las ciencias del espíritu ganadas en entender los texto en sus contextos, esto es, es su horizonte histórico, político, económico, social y cultura por ser precisamente el contexto, en tanto realidad multidimensional, donde emerge el sentido y significado de un discurso o de una narrativa; de modo que, al entender adecuadamente lo que un autor quiere expresar (por adecuado se destaca la no distorsión de su mensaje), se llega a captar por extensión las representaciones del tiempo y espacio del que forma parte, de lo que se puede inferir lógicamente que, cuando no se conoce el lugar de enunciación de un discurso difícilmente se puede decodificar su mensaje.

Desde la perspectiva hermenéutica no solo ya como filosofía, sino además como herramienta metodológicamente, el fenómeno epistemológico de la interpretación se erige en el acto primario de todo conocimiento científico o vulgar, por lo tanto, el conocer transcurre mediante un diálogo inter-temporal en la cual un exegeta formula un conjunto de preguntas a un texto-autor, estas preguntas son: ¿Qué quiere expresar el autor? ¿Qué ideología profesa? ¿Qué intereses defiende con su discurso? Por lo demás, operativamente el equipo de investigación participó en igualdad de condiciones en todas las fases de la investigación: a) selección del tema, b) arqueo de fuentes, c) selección de la piezas discursivas trabajadas y d) redacción del artículo científico. 


\section{Características del discurso progresista en el siglo 2021}

No es suficiente hablar del discurso progresista en abstracto tal como lo supone la metodología hermenéutica que vincula los textos a su contexto de producción, para poder entenderlos; en consecuencia, el discurso progresista es un fenómeno histórico concreto que solo puede ser conocido y estudiado, mediante las narrativas de los actores políticos y sujetos sociales que se adhieren a su núcleo argumentativo y se expresan según sus estándares. Sin embargo, como ya se afirmó en un primer momento se trata de una formación discursiva que se identifica por:

1. Manifestar su antagonismo a los poderes tradicionales del estado, la iglesia, la academia, los medios de comunicación y las finanzas, por suponer a priori que están al servicio irrestricto de los intereses hegemónicos que buscan en cada momento someter y subordinar permanentemente a la ciudadanía.

2. Apostar por formas de democracia de base que maximizan las capacidades comunitarias de asociación, organización y movilización en la defensa de los legítimos intereses de personas y grupos diversos, históricamente marginados y explotados, como las mujeres, los extranjeros, los pobres, los negros, los indígenas y los homosexuales, entre otros.

3. Revindicar las formas de producción no capitalistas que, por un lado, apuestan al desarrollo sostenible y, por el otro, reducen el afán de lucro a la satisfacción de las necesidades humanas. Al igual que los socialistas clásicos, la mayoría de los progresistas de hoy suponen que el capitalismo es el centro de las desigualdades materiales y simbólicas en las sociedades modernas, de ahí que apuesten por el cooperativismo, la economía naranja, la economía social de mercado o el llamado socialismo liberal en el marco de una economía mixta.

4. Aportar herramientas ideológicas para frenar el accionar de las hegemonías políticas, económicas y sociales que suponen oprimen de forma material y mental a comunidades enteras, bien sea denunciando su situación de víctimas y al mismo tiempo impulsando la lucha para su consecuente liberación.

5. Yuxtaponer la retórica a la realidad concreta, de modo que ciertos gobiernos que se presentan por ante la opinión pública como progresista intentan más bien crear una hegemonía cultural en la cual los discursos importen más que los logros y resultados de su gestión. En este sentido, son comunes en esta operación ideológica la propaganda, la censura y la crítica violenta a todas las fuentes de información que no se pliegan a los parámetros de su agenda de poder. 
Krylova Svitlana, Lesia Levchenko, Sulieimanova Liia, Ulyana Khanas y Larysa Kharchenko Apuntes para la crítica del discurso progresista históricamente existente

6. Usar selectivamente el pensamiento crítico, de modo que la crítica solo se aplique a la revisión del accionar cotidiano de las personas y agrupaciones opositoras y, casi nunca, como autocritica, para determinar los aspectos a mejorar y fortalecer internamente.

7. Adversar la ideología liberal por considerar, al igual que los marxistas, que es el núcleo epistemológico de las elites en el poder, del patriarcado y de la sociedad moderna en general, como máxima expresión de la alienación y del consumismo.

8. La transferencia de responsabilidades propias a terceros o entidades indeterminadas como: la derecha internacional, la burguesía capitalista o los enemigos del pueblo.

En este orden de ideas, como se verá en el apartado que sigue los actores políticos y sujetos sociales identificados por producir discursos progresistas son aquellos que, sin importar su lugar de enunciaron o sus referentes ideológicos particulares, construyen un discurso a tono con al menos 6 de las características descritas como indicadores centrales de esta formación discursiva. No se descarta que en posteriores investigaciones se puedan postular otros indicadores adicionales que vendrían engrosar este menú teórico. Además, tampoco se puede desconocer que algunas características como las (a, b y e), no son exclusivas de los progresistas y también pueden manifestarse, con algunos matices, en el discurso de liderazgos neoconservadoras o neopopulistas.

\section{Hegemonía y discurso en casos concretos}

La muestra de los discursos seleccionados de forma intencional y no aleatoria son de tres personajes de izquierda con amplia trayectoria política y con una estructurada hegemonía ${ }^{9}$ en sus respectivas sociedades, nos referimos a: Nicolas Maduro Moros, presidente de Venezuela; Alberto Fernández, presente de Argentina y; el excomandante guerrillero Daniel Ortega, presidente de Nicaragua. Seguros estamos que en futuros estudios la muestra se extenderá también a otras latitudes incluyendo personas de Europa, en función de elaborar un análisis comparado.

En al caso de presidente Nicolas Maduro destaca para los autores de este artículo ubicados en Europa del este, por el hecho de que sea el primer presidente del continente americano que lidere un gobierno sindicado por la fiscalía de la Corte Penal Internacional (CPI) de haber cometido,

9 Simplemente se entiende por hegemonía la supremacía en términos de poder y autoridad que dentro de un sistema políticos ejercen unos grupos sobre otros. No se descarta que esta supremacía sea violenta y que comúnmente se constituya en un óbice para el goce y disfrute de los derechos fundamentales en poblaciones marginadas o subalternas. 
posiblemente, crímenes de lesa humanidad, por la supuesta práctica deliberada y sistemática de delitos como: ejecuciones extrajudiciales, detenciones arbitrarias y torturas (Singer, 2021); no obstante, el líder suramericano se caracteriza por pronunciar continuamente discursos a tono con el ideal progresista.

Una muestra de las piezas retoricas del presidente de Venezuela está en su discurso pronunciado recientemente por ante la Asamblea General de la ONU, en la cual en un video grabado de 20 minutos de duración denuncia, las que a su juicio son "sanciones criminales" contra el pueblo de Venezuela impuestas por Estados Unidos y sus socios europeos:

Se persiguen las cuentas financieras. Se nos ha secuestrado y bloqueado el oro de las reservas internacionales legales del Banco Central de Venezuela en Londres. Se nos ha secuestrado y bloqueado miles de millones de dólares en cuentas bancarias de Estados Unidos, Europa y más allá (Maduro, citado por: Ocando, 2021: $\mathrm{s} / \mathrm{p}$ ).

Al tiempo que agregó: "Le decimos a los pueblos del mundo con valentía, decisión, inteligencia y sabiduría sí se pueden afrontar las agresiones imperiales y avanzar", dijo, haciendo votos por el multipluralismo, "sin hegemonismos imperiales" (Maduro, citado por: Ocando, 2021: s/p).

Si bien es cierto que las sanciones implementadas desde 2017 han detenido un efecto perturbador sobre la estabilidad económica venezolana, queda claro que, en buena medida fueron las políticas económicas del fallecido presidente Chaves y su sucesor Maduro, caracterizadas por controles de cambio, controles de precios y subsidio general a la sociedad, muy próximas a la experiencia de planificación centralizada de la economía acontecida en la URSS, las responsables principales de la actual situación de calamidad, tal como lo evidencia el hecho de que la crisis humanitaria compleja en Venezuela inicia mucho antes delas sanciones. En consecuencia, se trata de un discurso que intenta crear una versión muy poco realista de las verdaderas causas y consecuencias de la situación del otrora "país mas rico" de la América del sur.

Por su parte, el presidente de Argentina Alberto Fernández también se identifica por su vinculación a una narrativa que pretende socavar las bases escleróticas de la política tradicional para estar en completa sintonía con los parámetros del discurso progresista, con un énfasis especial en la reivindicación de los derechos canculcados históricamente a las personas y comunidades LGBT. En este sentido, en un discurso pronunciado como homenaje a César Cigliutti quien fuera uno de los lideres más emblemáticos de la comunidad gay en el país austral indicó:

Él fue un pionero en ese punto, definitivamente lo fue, y soy testigo de que lo fue. Y la verdad alguien que se anima a tanto, tanto es animarse a abrirle la cabeza a toda una sociedad y a decir: "admítanme como soy y denme 
Krylova Svitlana, Lesia Levchenko, Sulieimanova Liia, Ulyana Khanas y Larysa Kharchenko Apuntes para la crítica del discurso progresista históricamente existente

\section{los mismos derechos que ustedes tienen, porque yo no soy distinto" es un ser inmenso, inmenso. Y yo celebro que hoy esté su imagen, entre todos estos cuadros, porque claramente es un referente de una Argentina que queremos (Fernández, 2021: s/p) (negristas añadidas).}

Conviene remarcar que Fernández es, al menos en el caso del tema de la sexodiversidad y la igualdad de género, consecuente con su discurso, hasta el punto de que es Argentina el primer país de la región latinoamericana en crear un ID no-binario para incluir, aunque sea simbólicamente al conjunto de las personas que no se auto-perciben simplemente como hombre o mujer. A este respeto reseño la BBC New (2021: s/p) que:

Una de las primeras personas en recibir su Documento Nacional de Identidad (DNI) argentino con la nomenclatura no binaria fue Gerónimo Carolina González Devesa. De 35 años y profesional en medicina, González Devesa llevaba tres años de batallas para lograr el reconocimiento formal de su identidad no binaria.

Aunque los críticos de Fernández argumenten que la medida es más efectista que real ya que buena parte de los LGBT siguen viviendo en condiciones de emergencia social que vulneren sus derechos y su dignidad humana, todo indica que esta política significa un gran logro en términos de reconocimiento para todas las personas que reclaman para sí la posibilidad de desarrollar una sexualidad alternativa sin por ello tener que ser discriminados, estigmatizados o perseguidos, como ha venido sucediendo hasta ahora en buena parte del mundo desde el medioevo.

Otra cosa diferente, pero también valida científicamente, seria hacer una crítica interna al tema del discurso de la sexodiversidad y su núcleo central de la teoría de género, según la cual el sexo y el género son cosas diferentes que requieren, por lo tanto, tratamiento particular. En este sentido, la teoría de genero en boga afirma que universalmente este fenómeno es una construcción social que asigna arbitrariamente roles, estatus, atributos y ventajas a las personas y comunidades en términos biopolíticos para al mantenimiento y preservación de la sociedad de tipo patriarcal, ante lo cual habría que afirmar que el género, como concepto y realidad, no es solo una construcción social sino además biológica.

De modo que, la construcción individual de un género determinado nobinario como una forma heterodoxa de ser y estar en el mundo, no puede depender únicamente de la subjetividad auto-percibida, de lo contrario las sociedades contemporáneas se enfrentarían a problemas jurídicos irresolubles. Piénsense, por ejemplo, en el caso de un hombre biológico de 40 años que se auto-percibe como un chico de 8 años cंes valido que pueda ser novio de una niña biológica de 8 años? $\mathrm{O}$, imagínese el caso de un hombre biológico que se auto-percibe como mujer y se relaciona afectivamente con otra mujer biológica ¿Qué hacer si este hombre biológico golpea a su pareja mujer biológica? ¿Estaríamos ante un caso de violencia de género? De ser condenado por el delito ćdebe ser recluido en una cárcel de mujeres? En estos ejemplos, las limitaciones de la teoría de género son evidentes. 
Por último, Daniel Ortega Saavedra es un personaje que se aproxima en su devenir histórico a la arraiga tradición caudillista latinoamericana identificada por producir y reproducir continuamente liderazgos carismáticos que personalizan de forma radical la política y, al mismo tiempo, crean las condiciones de posibilidad, objetivas y subjetivas para erosionar la frágil arquitectura democrática de la región. Se trata de la emergencia continua de lideres populistas radicales o neoconservadores que construyen mediante su discurso un profundo vinculo afectivo con sus seguidores en el cual no hay espacios para la mediación institucional de tipo legal-racional de la que hablaba Max Weber, tal como advierte Castaño (2017).

El excomandante sandinista señalo en un discurso pronunciado con ocasión de la celebración del 42 aniversario de la revolución sandinista en Nicaragua que:

Aquí tenemos un Ejército que está para resguardar la soberanía nacional y también construir la seguridad y la lucha contra la delincuencia, contra el narcotráfico. Y tenemos una Policía que está dedicada de lleno también a la lucha por la seguridad ciudadana. Por eso les digo: el pueblo unido jamás será vencido y el pueblo armado jamás será aplastado... Aquí está Nicaragua de pie, firme y adelante, a pesar de que han querido destruir la economía y han asesinado sembrando el terror, han puesto en práctica el terrorismo en Nicaragua (Citado por: Voz de América, 2021: s/p) (negritas añadidas).

A pesar de que es difícil encasillar al discurso progresista en una o varias categorías ideológicas, ya que se trata de una narrativa de síntesis que combina a veces sin mucha coherencia distintas filosofías y tradiciones políticas, sin duda, se trata de un discurso socialista-nacionalista en el cual ocupan lugar importante las trajinadas nociones de pueblo, soberanía y unidad nacional frente a los supuestos enemigos externos del proceso revolucionario.

Tal como se puede apreciarse en la cita, Ortega emplea en muchos sentidos una noción de soberanía nacional limitada y parcializada porque, por un lado, no incluye a los nicaragüenses opositores a su gobierno, los cuales son más bien catalogados continuamente de "traidores a la patria" y; por el otro, no se trata de una soberanía que permita a la sociedad civil organizada acceder a los espacios de poder político para fiscalizar el ejercicio del poder o desarrollar iniciativas a contravía de la hegemonía.

En Ortega, como en la mayoría de los liderazgos socialista marxistas, todos las formas y manifestaciones de pensamiento crítico que busquen cuestionar legitimante al ejercicio del poder, de su poder, son automáticamente catalogadas con epítetos negativos, cerrando con ello toda posibilidad de diálogo nacional y pluralismo ideológico como es el deber ser de una sociedad democrática plena donde no se persigue a la disidencia. 
Del mismo modo, al menos en Latinoamérica, la concepción de soberanía que emana de este discurso es en muchos aspectos decimonónica, ya que implícitamente se trata de una idea en la cual se propaga el papel del estado como máxima expresión de la autoridad política y de la estabilidad social y no se fomenta, como seria el caso en una tradición democracia participativa, de base y deliberativa, la soberanía individual y la autodeterminación de la persona humana como fuerza creadora para el desarrollo la conciencia ciudadana.

\section{Conclusiones}

La crítica al discurso progresista puede ser interna o externa; en el primer caso, la investigación sobre el tema se concentra en examinar las contradicciones argumentativas, epistemológicas y lógicas de este discurso desde variados enfoques o perspectivas de análisis, como la teoría neoretórica, el análisis del discurso, la semiótica, la filología o la filosofía del lenguaje, entre otras. En el segundo, de lo que se trata es de valorar cualitativamente el modo como los actores de poder usan esta herramienta lingüística en función de sus propios intereses y sus estrategias de comunicación política.

Moralmente el discurso Progresista no es por si mismo malo, bueno, ni neutral, todo dependerá, en último término, de los gustos y preferencias de cada persona construidos mediante sus sesgos culturales y, más específicamente, al calor de los procesos de socialización política por los que han sido condicionado ontológicamente. Por lo tanto, más que una crítica del discurso progresista históricamente existente, conviene efectuar una revisión a la forma tendenciosa mediante la cual ciertos actores políticos usan este discurso para validar sus intereses hegemónicos en su contexto de actuación.

¿Cuáles son las principales inconsistencias del discurso progresista en líneas generales? ¿hasta qué punto estas inconsistencias pueden significar la justificación de prácticas autoritarias que contravienen el goce y disfrute de derechos fundamentales en personas y comunidades enteras? ¿es el discurso Progresista un producto cultural novedoso?

Ante la primera pregunta, toda la evidencia teórica y empírica recaba por esta investigación permite afirmar que las principales inconsistencias del discurso progresista están en el hecho de no hay completa sintonía en entre el acto comunicativo y lo sucedido en la realidad concreta de los mundos de vida de las personas comunes; por lo tanto, más que una expresión de la realidad en términos de lo que las personas más vulnerables quieren, desean y necesitan, se trata de enmascarar los fracasos de una gestión de gobierno y de transferir responsabilidades a factores abstractos como la "derecha 
internacional", "los fascistas" y los "enemigos de la patria", situación que es muy común en la tradición discursiva del siglo del XX.

Ante la segunda pregunta, podemos responder muy concretamente que estas inconsistencias discursivas pueden justificar en todo momento prácticas autoritarias de todo tipo, porque al negar a priori la legitimidad de las personas y grupos que legítimamente piensan diferente al poder hegemónico, se socaba las bases del diálogo que es la sabia vital de toda experiencia verdaderamente democrática y, la historia contemporánea mundial a demostrado que es en democracia únicamente donde puede desarrollarse el proyecto jurídico y axiológico de los derechos humanos, para resguardo de la dignidad por ante el uso arbitrario del poder político.

Finalmente, el discurso progresista no es necesariamente un producto novedoso hasta ahora desde el punto de vista teórico o epistemológico. Como ya se dijo en las páginas anteriores se trata de una narrativa de síntesis que agrupa distintas ideologías y tradiciones, que van desde el ecologismo y el animalismo, hasta la justicia social con equidad de género. Lo que puede resultar realmente novedoso, llegado el caso, es la capacidad de este discurso para ir estructurando palatinamente un nuevo pensamiento político que venga a superar definitivamente la impronta política del programa filosófico de la modernidad ilustrada que dio vida desde el siglo XVIII, en un proceso dialéctico, al liberalismo y al socialismo aun vigentes.

\section{Referencias Bibliográficas}

BBC News Mundo. 2021. "Personas no binarias: los nuevos documentos de identidad de Argentina con opción "X" inéditos en Latinoamérica" Disponible en Línea. En: https://www.bbc.com/mundo/noticiasamerica-latina-57924274. Fecha de consulta: 07/07/2021.

CASTAÑO GÓMEZ, Liliana. 2017. "Modelos teóricos que explican el liderazgo político” En: Cuestiones Políticas. Vol. 33, No. 58. Disponible en Línea. En: https://produccioncientificaluz.org/index.php/cuestiones/article/ view/22975. Fecha de consulta: 07/12/2020.

ECHEVERRÍA, Rafael. 2003. Ontología del lenguaje. JC Sáez editor. Santiago de Chile, Chile.

FERNÁNDEZ, Alberto. 2021. "Palabras del presidente de la Nación, Alberto Fernández, en el acto dehomenaje a César Cigliutti, quien fuera presidente de la Comunidad Homosexual Argentina (CHA) y pionero en la lucha contra las discriminaciones" En: Casa Rosada. Disponible en línea. En: https://www.casarosada.gob.ar/informacion/discursos/47289palabras-del-presidente-de-la-nacion-alberto-fernandez-en-el-acto- 
de-homenaje-a-cesar-cigliutti-quien-fuera-presidente-de-la-comunidad-homosexual-argentina-cha-y-pionero-en-la-lucha-contra-lasdiscriminaciones-en-nuestro-pais-desde-antesala-del-salon-de-m. Fecha de consulta: 03/07/2021.

GADAMER, Hans-Georg. 1993. Verdad y método Fundamentos de una hermenéutica filosófica. Ediciones Sígueme. Salamanca, España.

LYOTARD, Jean-François. 1987. La condición postmoderna Informe sobre el saber. Ediciones Cátedra S.A. Madrid, España.

MUÑOZ, María Teresa. 2004. “El discurso político. Notas para un acercamiento wittgensteiniano" En: Signos Filosóficos. Vol. 6, No. 12, pp. 93-115.

NIKITENKO, Vitalina A; VORONKOVA, Valentyna H; ANDRIUKAITIENE, Regina; OLEKSENKO, Roman I. 2021. "The crisis of the metaphysical foundations of human existenceas a global problem of post-modernityand the ways of managerial solutions" En: Propósitos y Representaciones. Disponible en linea. En: https://vb.lsu.lt/object/elaba:84034693/. Fecha de consulta:14/07/2021.

OCANDO ALEX, Gustavo. 2021. "Maduro pide antela ONU el cese de "sanciones criminales" a Venezuela" En: VOA. Disponible en línea. En: https:// www.vozdeamerica.com/a/maduro-pide-ante-la-onu-en-mensajegrabado-el-cese-de-sanciones-criminales-a-venezuela/6241555.html. Fecha de consulta: 03/08/2021.

SCHIFFRIN, Deborah. 2011. "Definiciones de discurso" En: Revista de Investigación Educativa 13". Disponible en línea. En: https://www. uv.mx/cpue/num13/practica/completos/Schiffrin-Definiciones\%20 de\%20discurso.pdf. Fecha de consulta: 14/12/2020.

SINGER, Florantonia. 2021. "La Corte Penal Internacional investigará a Venezuela por crímenes de lesa humanidad" En: El País. disponible en línea. En: https://elpais.com/internacional/2021-11-o3/la-cortepenal-internacional-investigara-a-venezuela-por-crimenes-de-lesahumanidad.html. Fecha de consulta: 03/07/2021.

SOLER COSTA, Rebeca. 2011."El discurso político como marco de relaciones de poder asimétricas" En: Tejuelo. Didáctica de la lengua y la literatura. Año IV, No. 11, pp. 128-143.

VASILACHIS DE GIALDINO, Irene. 1998. Discurso político y prensa escrita, un análisis sociológico, Jurídico y lingüístico. Gedisa editorial. Barcelona, España. 
Vol. 39 N $^{\circ} 71$

Esta revista fue editada en formato digital y publicada en diciembre de 2021, por el Fondo Editorial Serbiluz, Universidad del Zulia. Maracaibo-Venezuela 